\title{
TUMOROUS ABNORMALITIES OF ADIPOSE TISSUE
}

\author{
J. Shafar, M.D., M.R.C.P., D.P.H. \\ Consultant Physician.
}

\author{
G. BEHR, M.R.C.P., F.C.Path. \\ Consultant Pathologist.
}

Burnley and District Group of Hospitals.

THE TERM "lipopathy" is used by Lever (1963) as applying to a group of unrelated disorders of fatty tissue, particularly of the subcutaneous fat, whereas Williams and Glomset (1962) employ it to designate any condition of abnormal fat metabolism. Localised or unusual depositions of fat may be classified as lipomatosis to distinguish them from ordinary obesity (Cannon, 1950).

Fat cells are found in the subcutaneous tissue of the entire body with the exception of the eyelids, penis, scrotum, and labia minora. Tumorous abnormalities of the adipose tissue may occur in the following forms:

Lipomas and liposarcomas;

Lipogranulomatosis;

Multiple diffuse lipomatosis;

Gardner's syndrome;

Systemic multicentric lipoblastosis;

Hibernoma.

Lipomas form the commonest soft-tissue tumours of the extremities, being especially frequent in the region of the shoulder and upper thigh, although they are observed in almost any part of the body. $12 \%$ of the tumours are multiple (2-6) (Bick, 1936). Liposarcoma in contrast is rare, and only in very few instances has it been reported to arise in a pre-existing lipoma. Recurrent lipomas are often liposarcomas from the beginning (Stout, 1944). Mixed mesodermal growths with a fat-tissue component are classified as mesenchymomas, representing developmental disorders rather than true lipoblastic tumours (Tedeschi and Lyon, 1957).

Lipogranulomatosis is an inclusive term indicating the presence of fat in a granulomatous reaction following local injury, injection of medicaments, ischæmia or inflammation. In the acute phase the features of inflammation may be evident, but later a nodular mass persists, showing attachment to the skin and a predisposition to calcification (Coventry, 1954).

In the condition of multiple diffuse lipomatosis numerous lipomas are present not only on the extremities but also on the trunk.

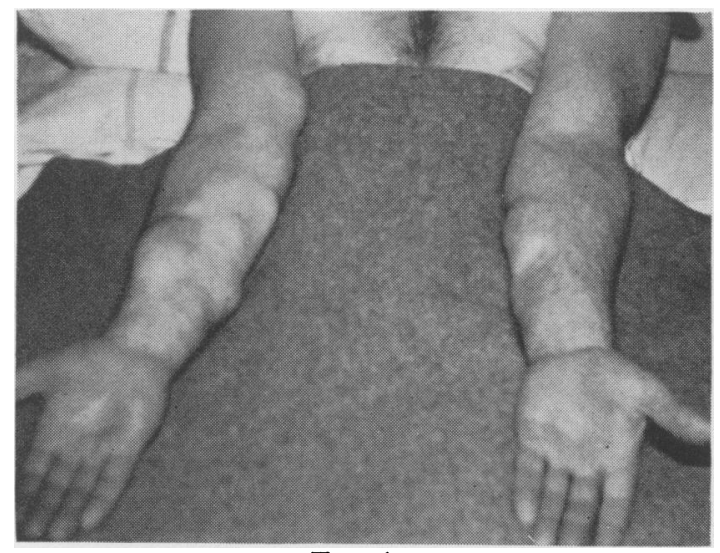

Fig. 1.

Their number may range in the hundreds. A hereditary incidence is not infrequent, with a dominant mode of transmission. It shows a male preponderance, and the age of onset varies considerably, so that the first appearance of a lipoma may precede puberty or be delayed until after the age of forty. A symmetrical distribution occurs so frequently that it is described by some as "diffuse symmetrical lipomatosis" (Gray and Jones, 1957). Occasionally the tumours are distributed in linear fashion along the course of peripheral nerves. Pain and tenderness are uncommon features but are present in a minority while the tumour is growing, disappearing when it reaches its full size. Fresh tumours make their appearance relatively suddenly and usually attain the maximal size in a short time. On chemical analysis the tumours consist of normal fat, identical in composition with that of the subcutaneous fatty tissue. Serum total and free cholesterol, lipids and phospholipids are normal (Shanks, Paranchych and Tuba, 1957). The general health remains unaffected and the tumours cause no concern except for cosmetic reasons or because of an unfortunate location resulting in mechanical interference with normal function. Confusion with neurofibromatosis is 
a common diagnostic error. This was the diagnosis offered in the example illustrated here (Fig. 1) by a consultant physician and a consultant surgeon who had examined the patient on separate occasions. The history in this instance had so far extended over 15 years, fresh tumours arising at varied intervals. While no specific symptoms arose as a consequence of the lesions, the patient had developed considerable anxiety concerning their possible malignant character. One of the swellings was therefore removed and examination revealed a simple lipoma.

An association of multiple subcutaneous lipomas with enormous fat pads over the rectus muscle and under the chin is recorded by Gray and Jones (1959). Kurweg and Spencer (1951) considered that the simultaneous presence of other conditions, such as palmar and plantar tylosis and multiple telangiectasia is probably coincidental.

In contrast is the condition of Gardner's syndrome (Gardner and Richards, 1953): hereditary polyposis of the rectum and colon associated with abnormal growths elsewhere in the body-in the skeletal system, particularly in the skull, and in the soft tissues, especially the subcutaneous, mesenteric and retroperitoneal regions. The variety of tumours is remarkable and includes lipoma, fibroma, lipofibroma, fibrosarcoma, leiomyoma, epidermal cyst and bony exostosis. An interesting report is presented by Laberge, Sauer and Mayo (1957). The patient was originally treated for subacute bacterial endocarditis when a subcutaneous lipoma was noted in the left lumbar region. 4 years later he was successfully operated for multiple polyposis and carcinoma of the colon. At that time another lipoma was observed on the anterior abdominal wall. Two further lipomas had appeared when the patient was seen again 3 years later. After a further two years an operation was performed for a tumour of the mesentery which was found to consist of connective tissue with areas of fat necrosis.

From a review of the literature Laberge and others (1957) conclude that the association of colonic pcilyposis with other tumours is not fortuitous, and suggest that when multiple tumours are present, the possibility of polyposis of the colon should be entertained.

Systemic multicentric lipoblastosis constitutes a distinct entity to be differentiated from multiple lipomatosis. The subject has been analysed by Tedeschi (1946). Non-encapsulated fat-tissue growths appear in an unpredictable and disorderly manner involving subcutaneous tissue, internal cavities, bones and internal $\bar{z}$ organs. The rate of progress is slow, but $\stackrel{\AA}{\circledR}$ characteristically excision is followed by local. recurrence. Within the growth mature fat cells $\overrightarrow{\vec{F}}$ predominate; although the frequency of tran- $\stackrel{?}{?}$ sitional forms indicates an origin from undifferentiated mesenchymal cells, this origin $\frac{\bar{c}}{\bar{c}}$ is similar to the development of fat tissue $\frac{\vec{\sigma}}{\vec{\sigma}}$ under normal conditions, and Tedeschi suggests $\unrhd$ that systemic multicentric lipoblastosis is a \% hyperplastic rather than a neoplastic process. $\vec{\circ}$

Systemic multicentric lipoblastosis contrasts $\vec{\overrightarrow{ }}$ with the benign nature of multiple subcutaneous $\vec{\omega}$ lipomas. The case reported by Tedeschi (1946) illustrates the gravity of the condition. An 3 apparently simple lipoma appeared in the popliteal space of this patient, and only after $\vec{A}$ the passage of 6 years was there evidence of $\vec{v}$ multicentric proliferation of fat tissue. A fatal $\overrightarrow{.}$ issue ensued after the lapse of a further 6 years. $\mathcal{G}$ A singular peculiarity of the case was an epidural location of one fatty mass, resulting $\vec{c}$ in paraplegia. Relief of the paralysis succeeded its removal, but it recurred twice, and death rapidly followed the third laminectomy.

Fat exists in the embryo in two forms $\overrightarrow{6}$ white and brown. White adipose tissue has universal distribution, but the occurrence $\%$ brown fat is limited to the interscapular, ce vical, axillary and perirenal areas. Probably brown fat is limited to the interscapular, cercell. In post-natal life no further formation $\frac{\circ}{\Phi}$ occurs and in the early post-natal phase trans- $\stackrel{\varrho}{\rightleftarrows}$ formation of the multilocular brown fat cell to the unilocular normal fat cell takes place. Adult brown fat displays these differences in distribution and gross and microscopic appearance. It also differs in its chemical constitution $\frac{0}{3}$ and its response to various physiological conditions, but no specific function has been attributed to this specialised tissue (Novy and Wilson, 1956). Hibernating animals show prominent collections of brown fat, but the 0 important role in hibernation formerly ascribed to brown fat is now discredited. The rare $\frac{D}{0}$ benign tumour of brown fat received the designation of hibernoma because of its similarity to $N$ the hibernating gland of animals. It presents $N$ clinically as a freely movable, firm, non- N tender swelling, and, as would be anticipated $\omega$ from the normal sites of brown fat, it occurs most frequently in the inter-scapular, cervical $\stackrel{0}{\odot}$ and axillary regions. It displays considerable $\stackrel{\mathcal{D}}{\rightleftharpoons}$ vascularity in contrast to the ordinary lipoma, and this is a useful guide to the clinical diagnosis. The tumour is encapsulated and of $\overrightarrow{\mathbb{D}}$ 


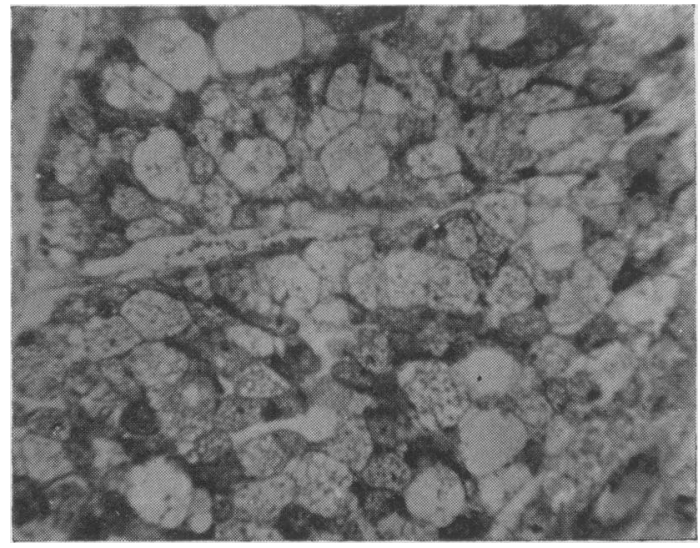

Fig. 2.

tan to brown colour. Removal is not attended by recurrence, but malignant degeneration, while rare, has been described.

We have seen 2 cases of hibernoma. The first one, occuring over the scapula in a man of 32 has been previously described (Jennings and Behr, 1955). The second one was found in a girl of 19 over the medial border of the left scapula. It had first been noticed 6 weeks previously and was thought to be getting larger. On examination there was a lobulated well defined swelling $8 \times 9 \mathrm{~cm}$. in size. On removal it was found to be very vascular, lobulated and of tan colour. Histological sections showed the typical multilocular fat cells. The photographs show this picture and the lobulation seen on cross section of the tumour. (Figs. 2 and 3).

\section{Summary}

The various tumorous abnormalities of adipose tissue are reviewed, and personal cases of multiple diffuse lipomatosis and hibernoma are described.

\section{REFERENCES}

Bick, E. M. (1963): Lipoma of the Extremities, Ann. Surg., 104, 139.

CanNon, J. F. (1950): Congenital Diffuse Lipomatosis, Ann. intern. med., 33, 1431.

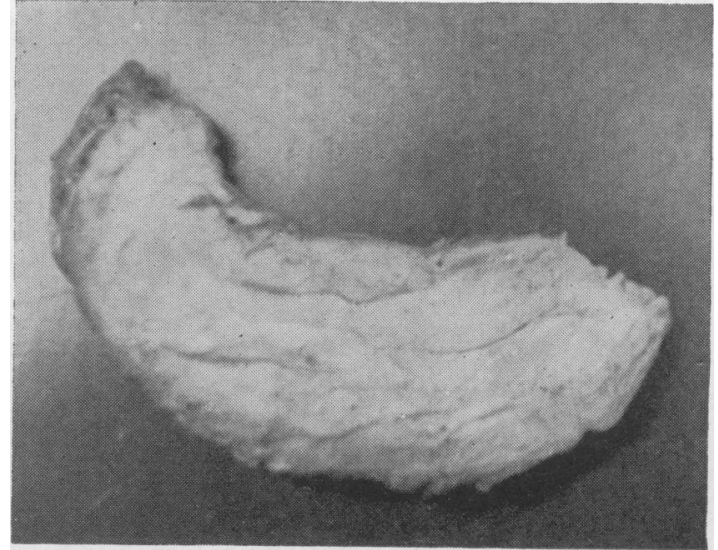

Fig. 3.

COVENTRY, M. B. (1954): Lipomatous Tumours of the Extremities, Amer. Acad. Orth. Surg., 11, 23.

GARDNER, E. J., and RICHARDS, R. C. (1953): Study of Multiple Cutaneous and Subcutaneous Lesions Occurring Simultaneously with Hereditary Polyposis and Osteomatosis, Amer. J. hum. Genet., 5, 139.

GraY, G., and Jones, H. (1959): A Case of Diffuse Symmetric Lipomatosis, Plast. reconstr. Surg., 23, 547.

JENNINGS, R. C., and BEHR, G. (1955): Hibernoma (Granular Cell Lipoma), J. clin. Path., 8, 310.

KURWEG, F. T., and SPENCER, R. (1951): Familial Multiple Lipomatosis, Amer. J. Surg., 82, 762.

LABerge, M. Y., Sauer, W. G., and MaYo, C. W. (1957): Soft Tissue Tumours Associated with Familial Polyposis, Proc. Mayo Clin., 32, 749.

LeVER, W. F. (1963): In Textbook of Medicine, edited by P. W. Beeson and W. McDermott, p. 1336. Philadelphia and London: W. B. Saunders.

Novy, F. G., and WILson, J. W. (1956): Hibernomas, Brown Fat Tumours, Arch. Derm., 73, 149.

Shanks, J., Paranchych, W., and Tuba, J. (1957): Familial Multiple Lipomatosis, Canad. med. Ass. J., 77, 881 .

Srout, A. P. (1944): Liposarcoma, Ann. Surg., 119, 86.

TeDESCHI, C. G. (1946): Systemic Multicentric Lipoblastosis, Arch. Path., 42, 320.

Tedeschi, C. G., and LyoN, W. H. (1957): Fat Tissue Growths, J. Mt. Sinai Hosp., 24, 1272.

Williams, R. H., and GlomSET, J. A. (1962): In Textbook of Endocrinology, edited by $\mathbf{R}$. $\mathbf{H}$. Williams, p. 942. Philadelphia and London: W. B. Saunders. 